\section{Are neck radiographs necessary in the management of croup syndrome?}

Sir,

A total of 115 children ( 83 boys and 32 girls) with croup syndrome were studied. Of these 110 had infective croup and five acute epiglottitis. The purpose of this study was to ascertain whether neck radiographs have any place in the diagnosis and management of croup syndrome in children. All except five with acute epiglottitis had chest and lateral neck radiographs on admission to hospital. Radiographs of 65 children, as expected, showed either ballooning of the hypopharynx or subglottic narrowing, or both, and no abnormality was found in the remaining 45 patients. The diagnosis of infective croup was mainly based on clinical presentation and acute epiglottitis was diagnosed on laryngoscopy. All children with acute epiglottitis required endotracheal intubation and all those with infective croup recovered with conservative management. Radiological findings of ballooning of the hypopharynx or subglottic narrowing did not help in the management of these children. If there is doubt about the diagnosis direc: inspection is the only appropriate method, provided adequate precautions are taken to deal with an emergency. Furthermore, the handling necessary to obtain adequate radiographs of the neck may be very disturbing and may precipitate acute airways obstruction. It seems, therefore, that neck radiographs do not help in the management of croup syndrome in children.

K M Goel Royal Hospital for Sick Children, Yorkhill, Glasgow G3 8SJ

\section{Danger of egg white treatment for nappy rash}

Sir,

We wish to report a possible hazard of a commonly used remedy for nappy rash.

A 6 month old boy, who at the age of 3 weeks had undergone bowel resection and afterwards developed lactose intolerance, was admitted to hospital for a lactose challenge. The challenge was unsuccessful and led to the development of profuse diarrhoea with acid stools. As a result he suffered severe excoriation of the buttocks which failed to respond to several proprietary preparations.

A favourite nursing treatment for nappy rash was then instituted, applying egg white to the affected area and nursing exposed. After two days the baby developed a florid urticarial rash covering his whole body and became generally unwell. The egg white treatment was stopped and within 24 hours the rash had resolved and the baby's condition improved. Serum IgE measured at the time was $183 \mathrm{IU} / \mathrm{ml}$ (normal less than $11 \mathrm{IU} / \mathrm{ml}$ ) and radio allergosorbent testing showed a class three response to egg.
It is well recognised that eggs are highly allergenic and in infants under 1 year of age, are probably the mosō common cause of urticaria due to ingestion of a foods allergen. ${ }^{1}$ It is not surprising, therefore, that the application of raw egg white to broken skin should facilitate theo development of hypersensitivity to egg, by allowing easye penetration of the allergen through the skin to the circulation.

We therefore question the wisdom of continuing the practice of applying egg white to excoriated buttocks whiches is so popular among paediatric nurses.

\section{Reference \\ 1 Twarog FJ. Urticaria in childhood: pathogenesis and manage ment. Pediatr Clin North Am 1983;30:891. \\ Juliet Court and LeE-Moy Nig Booth Hall Children's Hospital, Charlestown Roadico \\ Complete recovery after profound acidosis (pH 6.48)} Manchester M9 $2 A A$

Sir,

Khan et al have recently reported the successful resuscifition of a $21 / 2$ month old infant with an arterial blood $\mathrm{pH}$ 6.49 due to salicylate poisoning. ${ }^{1}$ We report a similar child with profound acidosis, although the duration of acidosis was even shorter in our patient.

A 5 week old Nigerian infant was circumcised by a $\frac{\alpha}{8}$ Mohel for religious reasons. The infant became fretful and $\stackrel{\varrho}{\rightarrow}$ during the ensuing night his mother changed three napkins $\overrightarrow{\overrightarrow{0}}$ soaked with blood. The Mohel was called to the home and 3 brought the child immediately to this hospital.

On arrival in casualty 10 hours after the circumcision the infant was extremely pale, peripherally cold, shocked, hypotonic, and unresponsive to painful stimuli. His rectalo temperature was $36^{\circ} \mathrm{C}$, heart rate $90 /$ minute, and blood $\%$ pressure was unrecordable. He bled excessively from 3 . puncture sites but there was no bruising or purpura. An arterial blood gas showed a $\mathrm{pH}$ of $6 \cdot 48, \mathrm{PCO}_{2} 40 \mathrm{~mm} \mathrm{Hg}$, 응 $\mathrm{PO}_{2} 63 \mathrm{~mm} \mathrm{Hg}, \mathrm{HCO}_{3} 2.7 \mathrm{mmol} / \mathrm{l}$ base excess $-33 \mathrm{mmol} / \mathrm{l}$ His haemoglobin concentration was $3 \cdot 2 \mathrm{~g} / \mathrm{dl}$, white cello count $18 \cdot 2 \times 10^{\circ} / 1$, and platelet count $264 \times 10^{\circ} / \mathrm{l}$. A coagula- $>$ tion screen performed concurrently showed a partialo thromboplastin time of greater than 140 seconds (control 36.5 seconds), a prothrombin time of 28 seconds (control $/ 0$ 13 seconds), a thrombin time of 13.5 seconds (control $10 \%$ seconds), and fibrinogen concentration of $1.2 \mathrm{~g} / \mathrm{l}$ (normal $2 \mathrm{~N}$ to $4 \mathrm{~g} / \mathrm{l})$. The diagnosis of classic haemophilia was $\omega$ subsequently confirmed (factor VIIIc concentration $3 \%$ ).

$\mathrm{He}$ was resuscitated with uncrossmatched (O rhesuso negative) blood, plasma, and sodium bicarbonate and five hours after admission his arterial blood gases showed a $\mathrm{pH} \stackrel{\varrho}{?}$ of $7 \cdot 248, \mathrm{PCO}_{2} 22.1 \mathrm{~mm} \mathrm{Hg}, \mathrm{HCO}_{3} 11.6 \mathrm{mmol} / \mathrm{l}$ and base 